УДК 616.89-008.441.13-055.1:616-092.6

Для цитирования: Прокопьева В.Д., Ярыгина Е.Г., Мандель А.И. Динамика окислительной модификации белков и липидов плазмы крови у больных алкоголизмом в процессе терапии. Сибирский вестник психиатрии и наркологии. 2017; 3 (96): 11 -15. https://doi.org/10.26617/1810-3111-2017-3(96)-11-15

\title{
Динамика окислительной модификации белков и липидов плазмы крови у больных алкоголизмом в процессе терапии
}

\section{Прокопьева В.Д., Ярыгина Е.Г., Мандель А.И.}

Научно-исследовательский институт психического здоровья

Томский национальный исследовательский медицинский центр Российской академии наук

Россия, 634014, Томск, ул. Алеутская, 4

\section{PEЗЮME}

Цель. Оценка динамики оксидативного статуса у больных в процессе антиалкогольной терапии для развития представлений об окислительном стрессе в клинике алкоголизма. Материалы и методы. В исследовании участвовало 46 больных алкоголизмом мужчин (F10.302) и 34 здоровых мужчин, составивших группу контроля. Для оценки оксидативного статуса пациентов до и после терапии в плазме крови определяли содержание продуктов окислительной модификации белков (ОМБ), измеряя карбонилированные белки, и продуктов перекисного окисления липидов (ПОЛ) с использованием тиобарбитуровой кислоты. Результаты. У пациентов с выраженным окислительным стрессом при поступлении на лечение терапия способствует его снижению. У пациентов без признаков окислительного стресса при поступлении после антиалкогольной терапии возможна индукция окислительной модификации белков и липидов в плазме крови. Заключение. В процессе антиалкогольной терапии в разных группах пациентов, отличающихся исходным оксидативным статусом, изменение маркеров окислительного стресса происходит разнонаправлено: при отсутствии у больного состояния окислительного стресса за время лечения может произойти его индукция, в то время как при выраженном окислительном стрессе в процессе персонализированной антиоксидантной терапии происходит его купирование.

Ключевые слова: окислительная модификация белков, перекисное окисление липидов, плазма крови, антиалкогольная терапия, алкоголизм.

Статья подготовлена в рамках выполнения медицинской технологии «Технология персонализированной антиоксидантной терапии больных алкоголизмом на основе оценки окислительного стресса».

\section{ВВЕДЕНИЕ}

При алкоголизме часто формируется окислительный стресс (ОС), в условиях которого белки, липиды, углеводы, нуклеиновые кислоты подвергаются окислительной модификации, теряя способность нормально функционировать $[1,2,3,4]$. Продукты такой модификации - карбонилированные, нитрозилированные и гликированные белки; агрегаты, полученные в результате кросс-линкинга белковых молекул; продукты перекисного окисления липидов; разные гибридные аддукты, дигидрогуанозин, гомоцистеин и др. служат маркерами окислительного стресса $[5,6]$. Согласно данным литературы, состояние ОС формируется при разных патологиях, и зачастую терапевтические стратегии предполагают подавление ОС [7]. Так, например, хорошо известно о применении антиоксидантов в медицинской практике. Рядом авторов, в частности, показано, что применение антиоксидантов в комплексном антиалкогольном лечении больных алкогольной зависимостью приводит к снижению выраженности ОС у пациентов $[8,9,10]$.

С другой стороны, установлено, что ОС для организма необходим, так как он играет существенную роль в иммунном ответе [11]. Высказывается также мнение, что в незначительных дозах окислительный стресс является полезным, так как проводит своеоб- разную тренировку организма и готовит его к встрече с более интенсивными стрессовыми условиями [12]. В ряде работ приводятся сведения о том, что не все окислительные модификации биомолекул вредны для организма, что карбонилирование, Sнитрозилирование и нитрование белков могут играть важную роль в процессе деградации поврежденных белков, что необходимо для нормального функционирования здоровых клеток [13, 14, 15]. Таким образом, купирование ОС не всегда может быть полезно для организма.

Ранее нами было отмечено, что использование антиоксидантной терапии при лечении больных алкогольной зависимостью может приводить к индукции ОС $[16,17]$.

С целью развития представлений об окислительном стрессе в клинике алкоголизма и повышения эффективности противоалкогольного лечения проведено расширенное исследование динамики маркеров окислительного стресса - карбонилов белков и продуктов ПОЛ - в плазме крови больных алкоголизмом до и после антиалкогольной терапии в зависимости от исходного оксидативного статуса пациентов.

\section{МАТЕРИАЛЫ И МЕТОДЫ}

В исследовании приняли участие 46 больных алкоголизмом мужчин, поступивших в отделение аддиктивных состояний НИИ психического здоровья Томского НИМЦ с диагнозом: Психические и поведенческие расстройства, вызванные употреблением алкоголя; абстинентное состояние (F10.302). Сред-

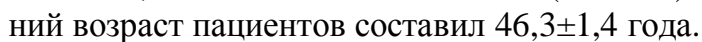


Забор крови осуществляли дважды: первый раз при поступлении больного в состоянии абстиненции до лечения, второй раз - через 2 недели, в течение которых проводили дезинтоксикацию. Медикаментозная терапия на этом этапе представлена церебро-, ангио- и гепатопротекторными средствами, антиоксидантами, тимолептическими препаратами - серотонинергическими антидепрессантами и антиконвульсантами для снижения патологического влечения к психоактивному веществу.

Для оценки оксидативного статуса пациентов до и после терапии в плазме крови определяли содержание продуктов окислительной модификации белков (ОМБ), измеряя карбонилированные белки по реакции с 2,4-динитрофенилгидразином [18], и продуктов перекисного окисления липидов (ПОЛ) с использованием тиобарбитуровой кислоты [19]. Измерение оптической плотности проб проводили на приборе Epoch (BioTek, США). За 100\% принимали средние показатели продуктов ОМБ и ПОЛ плазмы крови, полученной от 34 мужчин, составивших группу контроля. В эту группу включали здоровых мужчин, которые не состояли на учете у психиатра или нарколога, не имели хронических соматических заболеваний в стадии обострения и не употребляли алкоголь, по крайней мере последние 10 суток перед исследованием. Средний возраст в группе контроля составил $42,8 \pm 1,8$ года (разница со средним возрастом пациентов не достоверна, $\mathrm{p}=0,187)$. Контрольное значение

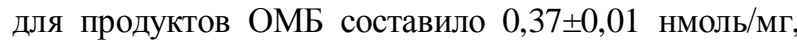
для продуктов ПОЛ - 2,56 $\pm 0,10$ нмоль/мл. Если у пациента уровень продуктов ПОЛ и/или ОМБ превышал средние контрольные значения более чем на $20 \%$, мы полагали наличие у больного состояние окислительного стресса. О купировании/активации ОС после проведенной терапии судили по снижению/повышению продуктов ОМБ и ПОЛ в плазме крови.

Статистическую обработку полученных результатов проводили с помощью пакета компьютерных программ «Statistica», версия 10 для Windows. Для проверки согласия с нормальным законом распределения количественных показателей использовали критерий Шапиро-Уилка. Данные рассчитывали по медиане $(\mathrm{Me})$ и межквартильному интервалу (QL$\mathrm{QU})$. Для оценки достоверности межгрупповых различий использовали непараметрический критерий Манна-У итни (Mann-Whitney, U test), для зависимой выборки - тест Вилкоксана (Wilcoxon). Статистически значимыми различия считали при $\mathrm{p}<0,05$.

\section{РЕЗУЛЬТАТЫ И ОБСУЖДЕНИЕ}

При оценке оксидативного статуса больных алкогольной зависимостью, поступивших на лечение в состоянии абстиненции, было обнаружено, что из 46 пациентов, принимавших участие в исследовании, у 14 человек оба показателя, характеризующих окислительную модификацию биомолекул (и продукты ОМБ, и продукты ПОЛ), не превышали средние контрольные значения более чем на $20 \%$, то есть у этих больных окислительный стресс не был выявлен (группа «Без ОС»). У других 32 пациентов было констатировано наличие окислительного стресса, причем у 14 из них оба измеряемые показателя (как ОМБ, так и ПОЛ) превышали средние контрольные значения более чем на $20 \%$ (группа «ОС по ОМБ и ПОЛ»). У 12 человек только показатель ПОЛ был выше контрольного уровня более чем на $20 \%$. При этом по ОМБ такого превышения не выявлено (группа «ОС по ПОЛ»). У 6 пациентов, напротив, такое превышение зафиксировано только по показателю ОМБ, но не по ПОЛ (группа «ОС по ОМБ»). После проведения антиалкогольного лечения у всех пациентов вновь измерили маркеры ОС в плазме крови, а затем в каждой группе пациентов провели статистическую оценку их динамики за время лечения. Результаты исследования представлены в таблице.

Т а б л и ц а

Динамика показателей ОМБ и ПОЛ плазмы крови пациентов алкогольной зависимостью в процессе лечения (1-я точка - до лечения, 2-я точка - после лечения, $\mathrm{n}$ - количество человек в группе)

\begin{tabular}{|c|c|c|c|c|}
\hline Группа & \multicolumn{2}{|c|}{ ПОЛ, нмоль/мЛ } & \multicolumn{2}{|c|}{ ОМБ, нмоль/мг } \\
\cline { 2 - 5 } доноров & 1 -я точка & 2 -я точка & 1 -я точка & 2 -я точка \\
\hline 3доровые & 2,50 & - & 0,37 & - \\
(контроль) & $(2,10-2,90)$ & & $(0,29-0,44)$ & \\
(n=34) & & & & \\
\hline Общая & 3,95 & 2,82 & 0,47 & 0,44 \\
(n=46) & $(3,10-5,10)$ & $(2,40-3,50)$ & $(0,38-0,53)$ & $(0,32-0,48)$ \\
$\mathrm{p}$ & $\# 0,000$ & $\# 0,013$ & $\# 0,001$ & $\# 0,072$ \\
& & $* 0,000$ & & $* 0,001$ \\
\hline ОС (ПОЛ и & 5,10 & 3,50 & 0,51 & 0,48 \\
ОМБ) (n=14) & $(4,37-5,30)$ & $(2,90-3,90)$ & $(0,49-0,54)$ & $(0,47-0,50)$ \\
$\mathrm{p}$ & $\# 0,000$ & $\# 0,001$ & $\# 0,000$ & $\# 0,001$ \\
& & $* 0,001$ & & $* 0,013$ \\
\hline ОС (ПОЛ) & 4,28 & 2,87 & 0,36 & 0,31 \\
(n=12) & $(4,10-5,26)$ & $(2,45-3,57)$ & $(0,32-0,38)$ & $(0,28-0,37)$ \\
$\mathrm{p}$ & $\# 0,000$ & $\# 0,041$ & $\# 0,555$ & $\# 0,165$ \\
& & $* 0,002$ & & $* 0,213$ \\
\hline ОС (ОМБ) & 2,89 & 3,07 & 0,47 & 0,34 \\
(n=6) & $(2,50-4,17)$ & $(2,80-3,50)$ & $(0,45-0,49)$ & $(0,27-0,38)$ \\
$\mathrm{p}$ & $\# 0,060$ & $\# 0,091$ & $\# 0,013$ & $\# 0,508$ \\
& & $* 0,893$ & & $* 0,043$ \\
\hline Без ОС & 3,10 & 3,15 & 0,31 & 0,35 \\
(n=14) & $(2,50-3,34)$ & $(2,40-4,63)$ & $(0,28-0,38)$ & $(0,33-0,43)$ \\
$\mathrm{p}$ & $\# 0,057$ & $\# 0,031$ & $\# 0,085$ & $\# 0,907$ \\
& & $* 0,382$ & & $* 0,030$ \\
\hline
\end{tabular}

Примечание. \# - Сравнение контроля и соответствующей точки; * - сравнение значений 1 -й и 2-й точек.

Согласно полученным результатам, в общей группе больных при поступлении (1-я точка) измеряемые показатели статистически значимо превышают соответствующие показатели в группе контроля (повышение статистически значимо как для ОМБ, так и для ПОЛ, в обоих случаях р<0,001). После лечения (2-я точка) в общей группе пациентов наблюдается снижение как ОМБ, так и ПОЛ (для обоих параметров различия между 1-й и 2-й точками статистически значимы, $\mathrm{p}<0,001)$. При этом значение ПОЛ остается достоверно выше контроля $(\mathrm{p}=0,013)$, в то время как для ОМБ различия с контрольными значениями становятся статистически не значимыми $(\mathrm{p}=0,072)$. Эти результаты хорошо согласуются с данными литературы. 
В частности в ранее опубликованных работах нами было показано, что антиалкогольное лечение больных алкоголизмом с включением антиоксиданта карнозина купирует окислительный стресс $[7,8]$. О снижении выраженности ОС в процессе терапии сообщается также и в других работах $[4,9,20]$.

В группах пациентов, которые поступили в отделение с окислительным стрессом, в процессе терапии произошли следующие изменения измеряемых показателей (см. таблицу). В группе с ОС по обоим показателям (ПОЛ и ОМБ) произошло снижение как значений ОМБ, так и ПОЛ, однако они и после терапии оставались достоверно выше контроля $(\mathrm{p}<0,001)$. В группе с ОС по показателю ПОЛ произошло снижение ПОЛ, при этом и после лечения этот показатель превышал контрольное значение $(\mathrm{p}=0,041)$. Показатель ОМБ в этой группе изменился статистически незначимо за время лечения, обнаружив лишь тенденцию к снижению. В группе больных с ОС по ОМБ произошло статистически значимое снижение ОМБ ( $p=0,043)$. При этом после лечения этот показатель достоверно не отличался от такового в группе контроля $(\mathrm{p}=0,508)$. Показатель ПОЛ в этой группе в 1-й точке статистически значимо не отличался от контроля. За время лечения он практически не изменился.

В группе без ОС измеряемые показатели изменялись в процессе терапии по-иному. Так, до лечения (в 1-й точке) в этой группе как показатель ПОЛ, так и показатель ОМБ достоверно не отличались от такового в группе контроля. За время лечения оба показателя несколько увеличились. При этом показатель ОМБ во 2-й точке достоверно вырос относительно 1-й точки (p=0,03), а увеличение ПОЛ было недостоверным, однако во 2-й точке этот показатель стал достоверно превышать таковой в группе контроля $(\mathrm{p}=0,031)$.

\section{ЗАКЮЧЕНИЕ}

Таким образом, в процессе антиалкогольной терапии в различных группах пациентов, отличающихся исходным оксидативным статусом, изменение маркеров окислительного стресса происходит разнонаправлено: при отсутствии у больного состояния окислительного стресса за время лечения может произойти его индукция, в то время как при выраженном окислительном стрессе в процессе персонализированной антиоксидантной терапии происходит его купирование.

\section{КОНФЛИКТ ИНТЕРЕСОВ}

Авторы заявляют об отсутствии конфликта интересов в связи с публикацией данной статьи.

\section{ИСТОЧНИК ФИНАНСИРОВАНИЯ}

Исследование проведено по теме, выполняемой в рамках поисковых научных исследований НИИ психического здоровья «Разработка методов персонализированной терапии у больных аддиктивными расстройствами». Шифр темы 0550-2016-0401. Номер госрегистрации АААА-А16-116042610053-7.

\section{СООТВЕТСТВИЕ ПРИНЦИПАМ ЭТИКИ}

Исследование проведено с соблюдением норм современной биомедицинской этики, включая получение от обследуемых информированного согласия на участие в исследовании и разрешения на использование их биопроб. Работа соответствует этическим стандартам, разработанным в соответствии с Хельсинской декларацией ВМА (протокол заседания Локального этического комитета при НИИ психического здоровья № 90 от 23 мая 2016 года, дело № 90/14.2016).

\section{ЛИТЕРАТУРА}

1. Прокопьева В.Д., Тюлина О.В. Окислительный стресс при алкоголизме. Сибирский вестник психиатрии и наркологии. 2004; 2: 61-66.

2. Das S.K., Vasudevan D.M. Alcohol-induced oxidative stress. Life Sci. 2007. 27; 81 (3): 177-187.

3. Parthasarathy R., Kattimani S., Sridhar M.G. Oxidative stress during alcohol with drawal and its relationship with drawal severity. Indian J. Psychol. Med. 2015; 37 (2): 175-80.

4. Бохан Н.А., Иванова С.А. Окислительный стресс при алкоголизме: возможности метаболической коррекции на этапе формирования ремиссии. Наркология. 2010; 9 (10): 45-49.

5. Halliwell B., Gutteridge J.M.C. Free Radicals in Biology and Medicine 4 ed. Oxford: Clarendon Press; 2007: 851.

6. Меньщикова Е.Б., Ланкин В.З., Зенков Н.К. Окислительный стресс. Прооксиданты и антиоксиданты. М.: Слово, 2006: 556.

7. Prokopieva V.D., Yarygina E.G., Bokhan N. A., Ivanova S.A. Use of Carnosine for Oxidative Stress Reduction in Different Pathologies. Oxidative Medicine and Cellular Longevity. 2016; Article ID 2939087: 8 .

8. Прокопьева В.Д., Бохан Н.А., Патышева Е.В., Ярыгина Е.Г., Сафиуллина В.В., Молькина Л.Г., Ляшенко Г.П. Оценка выраженности окислительного стресса у больных алкоголизмом и его коррекция с помощью Севитина. Сибирский вестник психиатрии и наркологии. 2007; 2 (45): 37-40.

9. Бохан Н.А., Мандель А.И., Аболонин А.Ф., Ляшенко Г.П., Кисель Н.И., Молькина Л.Г., Бойко А.С., Иванова С.А. Реамберин в комплексной терапии абстинентного синдрома у больных алкоголизмом. Клиническая медицина. 2012; 11: $57-62$.

10. Жернова Е.В., Вялова Н.М., Иванова С.А., Бохан Н.А. Показатели запрограммированной гибели лимфоцитов и нейтрофилов у лиц с алкогольной интоксикацией в динамике терапии препаратом с антиоксидантными свойствами. Вестник Томского государственного педагогического университета. 2009; 3: 59-62.

11. Хаитов Р.М., Игнатьева Г.А., Сидорович И.Г. Иммунология. Норма и патология. М.: Медицина, 2010: 752.

12. http://immunar.ru/med-novosti/polza-okislitelnogo-stressa/

13. Valko M., Leibfritz D., Moncol J., Cronin M.T., Mazur M., Telser J. Free radicals and antioxidants in normal physiological functions and human disease. Int. J. Biochem. Cell. Biol. 2007. $39(1): 44-84$.

14. Wong C.M., Marcocci L., Liu L., Suzuki Y.J. Cell Signaling by Protein Carbonylation and Decarbonylation. Antioxidants \& Redox Signaling. 2010; 12 (3): 393-404.

15. Janssen-Heininger Y.M., Mossman B.T., Heintz N.H., Forman H.J., Kalyanaraman B., Finkel T., Stamler J.S., Rhee S.G., van der Vliet A. Redox-based regulation of signal transduction: principles, pitfalls, and promises. Free Radic. Biol. Med. 2008. 45 (1): $1-17$.

16. Прокопьева В.Д., Мандель А.И., Ярыгина Е.Г. Технология персонализированной антиоксидантной терапии больных алкоголизмом на основе оценки окислительного стресса: Медицинская технология. Томск: «Иван Федоров», 2016: 22.

17. Прокопьева В.Д., Мандель А.И., Ярыгина Е.Г. Персонализированная антиоксидантная терапия при алкогольной зависимости. Наркология. 2017; 16 (6): 31-35.

18. Levine R.L. Carbonyl modified proteins in cellular regulation, aging and disease. Free Radic. Biol. Med. 2002; 32: 790-796. 
19. Коробейникова Э.Н. Модификация определения продуктов перекисного окисления липидов в реакции с тиобарбитуровой кислотой. Клиническая лабораторная диагностика 1989; 7: 8-9.

20. Мингазов А.Х., Бохан Н.А., Кривулин Е.Н., Бабин К.А., Шатрова Ю.М., Виноградов Д.Б. Гендерные особенности окислительной модификации белков плазмы крови больных алкоголизмом позднего возраста. Сибирский вестник психиатрии и наркологии. 2013; 3 (78): 9-13.

Поступила в редакцию 11.05.2017

Утверждена к печати 26.06.2017

Прокопьева Валентина Даниловна, д-р биол. наук, в.н.с. лаборатории клинической психонейроиммунологии и нейробиологии. Ярыгина Екатерина Григорьевна, к.б.н., н.с. лаборатории клинической психонейроиммунологии и нейробиологии.

Мандель Анна Исаевна, д.м.н., проф., в.н.с. отделения аддиктивных состояний.

Прокопьева Валентина Даниловна, valyaprok@mail.ru

УДК 616.89-008.441.13-055.1:616-092.6

For citation: Prokopieva V.D., Yarygina E.G., Mandel A.I. Dynamics of oxidative modification of proteins and lipids of blood plasma in alcoholic patients in the process of the therapy. Siberian Herald of Psychiatry and Addiction Psychiatry. 2017; 3 (96): 11-15. https://doi.org/10.26617/1810-3111-2017-3(96)-11-15

\section{Dynamics of oxidative modification of proteins and lipids of blood plasma in alcoholic patients in the process of the therapy

\author{
Prokopieva V.D., Yarygina E.G., Mandel A.I.
}

Mental Health Research Institute, Tomsk National Research Medical Center, Russian Academy of Sciences Aleutskaya Street 4, 634014, Tomsk, Russian Federation

\section{ABSTRACT}

Objective: to evaluate dynamics of oxidative status in patients in the process of antialcohol therapy for development of ideas about oxidative stress in the clinical picture of alcoholism. Materials and Methods: The study enrolled 46 male alcoholic patients (F10.302) and 34 healthy men (control group). For evaluation of oxidative status of patients at baseline and after therapy blood plasma was used for determining the content of products of the protein oxidative modification (POM), measuring carbonylated proteins, and products of lipid peroxidation (LP), using thiobarbituric acid. Results: In patients with severe oxidative stress at baseline the therapy contributed to its reduction. In patients without signs of oxidative stress at baseline after antialcohol therapy the induction of oxidative modification of proteins and lipids in blood plasma was possible. Conclusion: In the process of antialcohol therapy in different groups of patients with different initial oxidative status, change of markers of oxidative stress occurred differently directed: in patient without state of oxidative stress during therapy its induction could occur while in case of severe oxidative stress its reduction occurred in the process of personalized antioxidant therapy.

\section{Keywords: protein oxidative modification, lipid peroxidation, blood plasma, antialcohol therapy, alcoholism.}

\section{REFERENCES}

1. Prokopieva V.D., Tyulina O.V. Okislitel'nyy stress pri alkogolizme [Oxidative stress in alcoholism]. Sibirskiy vestnik psikhiatrii i narkologii - Siberian Herald of Psychiatry and Addiction Psychiatry. 2004; 2: 61-66 (in Russian).

2. Das S.K., Vasudevan D.M. Alcohol-induced oxidative stress. Life Sci. 2007. 27; 81 (3): 177-187.

3. Parthasarathy R., Kattimani S., Sridhar M.G. Oxidative stress during alcohol with drawal and its relationship with withdrawal severity. Indian J. Psychol. Med. 2015; 37 (2): 175-80.

4. Bokhan N.A., Ivanova S.A. Okislitel'nyy stress pri alkogolizme: vozmozhnosti metabolicheskoy korrektsii na etape formirovaniya remissii [Oxidative stress in alcoholism: possibilities of metabolic correction at the stage of remission formation]. Narkologiya - Narcology. 2010; 9 (10): 45-49 (in Russian).

5. Halliwell B., Gutteridge J.M.C. Free Radicals in Biology and Medicine 4 ed. Oxford: Clarendon Press; 2007: 851.

6. Menshchikova E.B., Lankin V.Z., Zenkov N.K. Okislitel'nyy stress. Prooksidanty i antioksidanty [Oxidative stress. Prooxidants and antioxidants]. M.: Slovo, 2006: 556 (in Russian).

7. Prokopieva V.D., Yarygina E.G., Bokhan N. A., Ivanova S.A. Use of Carnosine for Oxidative Stress Reduction in Different Pathologies. Oxidative Medicine and Cellular Longevity. 2016; Article ID 2939087: 8 .

8. Prokopieva V.D., Bokhan N.A., Patysheva E.V., Yarygina E.G., Safiullina V.V., Mol'kina L.G., Lyashenko G.P. Otsenka vyrazhennosti okislitel'nogo stressa u bol'nykh alkogolizmom i ego korrektsiya s pomoshch'yu Sevitina [Evaluation of severity of oxidative stress in alcoholic patients and its correction with $\mathrm{Se}$ vitin]. Sibirskiy vestnik psikhiatrii i narkologii - Siberian Herald of Psychiatry and Addiction Psychiatry 2007; 2 (45): 37-40 (in Russian).

9. Bokhan N.A., Mandel A.I., Abolonin A.F., Lyashenko G.P., Kisel' N.I., Mol'kina L.G., Boiko A.S., Ivanova S.A. Reamberin $\mathrm{v}$ kompleksnoy terapii abstinentnogo sindroma u bol'nykh alkogolizmom [Reamberin in complex therapy of withdrawal syndrome in alcoholic patients]. Klinicheskaya meditsina - Clinical Medicine. 2012; 11: 57-62 (in Russian).

10. Zhernova E.V., Vyalova N.M., Ivanova S.A., Bokhan N.A. Pokazateli zaprogrammirovannoy gibeli limfotsitov i neytrofilov u lits $\mathrm{s}$ alkogol'noy intoksikatsiey $\mathrm{v}$ dinamike terapii preparatom $\mathrm{s}$ antioksidantnymi svoystvami [Parameters of programmed death of lymphocytes and neutrophils in persons with alcohol intoxication in dynamic of therapy preparation with antioxidant properties]. Vestnik Tomskogo gosudarstvennogo pedagogicheskogo universiteta - Tomsk State Pedagogical University Bulletin. 2009; 3: 5962 (in Russian)

11. Khantov R.M., Ignatieva G.A., Sidorovich I.G. Immunologiya. Norma i patologiya [Immunology. Norm and Pathology]. M.: Meditsina, 2010: 752 (in Russian).

12. http://immunar.ru/med-novosti/polza-okislitelnogo-stressa/ (in Russian).

13. Valko M., Leibfritz D., Moncol J., Cronin M.T., Mazur M., Telser J. Free radicals and antioxidants in normal physiological functions and human disease. Int. J. Biochem. Cell. Biol. 2007. 39 (1): 44-84. 
14. Wong C.M., Marcocci L., Liu L., Suzuki Y.J. Cell Signaling by Protein Carbonylation and Decarbonylation. Antioxidants \& Redox Signaling. 2010; 12 (3): 393-404.

15. Janssen-Heininger Y.M., Mossman B.T., Heintz N.H., Forman H.J., Kalyanaraman B., Finkel T., Stamler J.S., Rhee S.G., van der Vliet A. Redox-based regulation of signal transduction: principles, pitfalls, and promises. Free Radic. Biol. Med. 2008. 45 (1): 1-17.

16. Prokopieva V.D., Mandel A.I., Yarygina E.G. Tekhnologiya personalizirovannoy antioksidantnoy terapii bol'nykh alkogolizmom na osnove otsenki okislitel'nogo stressa: Meditsinskaya tekhnologiya [Technology of personalized antioxidant therapy of alcoholic patients based on evaluation of oxidative stress. Medical technology]. Tomsk: Ivan Fedorov, 2016: 22 (in Russian).

17. Prokopieva V.D., Mandel A.I., Yarygina E.G. Personalizirovannaya antioksidantnaya terapiya pri alkogol'noy zavisimosti [Personalized antioxidant therapy in alcohol dependence]. Narkologiya - Narcology. 2017; 16 (6): 31-35 (in Russian).

18. Levine R.L. Carbonyl modified proteins in cellular regulation, aging and disease. Free Radic. Biol. Med. 2002; 32: 790-796.

19. Korobeinikova E.N. Modifikatsiya opredeleniya produktov perekisnogo okisleniya lipidov $\mathrm{v}$ reaktsii $\mathrm{s}$ tiobarbiturovoy kislotoy [Modification of determining the products of lipid peroxidation in reaction with thiobarbituric acid]. Klinicheskaya laboratornaya diagnostika - Clinical Laboratory Diagnostics. 1989; 7: 8-9 (in Russian).

20. Mingazov A.Kh., Bokhan N.A., Krivulin E.N., Babin K.A., Shatrova Yu.M., Vinogradov D.B. Gendernye osobennosti okislitel'noy modifikatsii belkov plazmy krovi bol'nykh alkogolizmom pozdnego vozrasta [Gender characteristics of blood plasma oxidative protein modification among older drinkers]. Sibirskiy vestnik psikhiatrii i narkologii - Siberian Herald of Psychiatry and Addiction Psychiatry. 2013; 3 (78): 9-13 (in Russian).

Received May 11.2017 Accepted June 26.2017

Prokopieva Valentina D., ScD, leading researcher of the Laboratory of Clinical Psychoneuroimmunology and Neurobiology, Mental Health Research Institute, Tomsk National Research Medical Center, Russian Academy of Sciences, Tomsk, Russian Federation.

Yarygina Ekaterina G., Candidate of Biological Sciences, researcher of the Laboratory of Clinical Psychoneuroimmunology and Neurobiology, Mental Health Research Institute, Tomsk National Research Medical Center, Russian Academy of Sciences, Tomsk, Russian Federation.

Mandel Anna I., MD, Prof., leading researcher of Addictive States Department, Mental Health Research Institute, Tomsk National Research Medical Center, Russian Academy of Sciences, Tomsk, Russian Federation.

Prokopieva Valentina D., valyaprok@mail.ru 